\title{
OÚRICUR'
}

\section{ÍNDIOS: DESAFIOS AS PESQUISAS E AS REFLEXÕES HISTÓRICAS}

\author{
Edson SILVA ${ }^{1 *}$
}

\begin{abstract}
${ }^{1}$ Professor Titular de História na UFPE. Doutor em História Social pela UNICAMP. Leciona História no Colégio de Aplicação/Centro de Educação-UFPE. Professor no Mestrado Profissional em Ensino de História/PROFHISTÓRIA-UFPE e no Programa de Pós-Graduação em História/UFCG (Campina GrandePB). *Autor correspondente. E-mail: edson.edsilva@hotmail.com

Recebido: 23.10.2019 Aceito: 27.05.2020

http://doi.org/10.29327/ouricuri.9.2-3
\end{abstract}

\begin{abstract}
Resumo: Diversos estudos foram elaborados nos últimos vinte anos sobre os chamados "índios misturados" no Nordeste. Grupos mobilizados desde as primeiras décadas do século XX por reivindicações de direitos, colocando em questão crenças e afirmações sobre o desaparecimento indígena na Região, e que conquistaram considerável visibilidade sociopolítica em anos recentes. Constituindo-se, portanto, em um tema a ser discutido na área de História, malgrado ainda preconceitos e o quase desconhecimento, expresso ainda pelas poucas pesquisas sobre o assunto, nessa área de estudo. A partir de uma pesquisa realizada sobre os Xukuru do Ororubá, habitantes em Pesqueira e Poção/PE, buscamos evidenciar como os indígenas apoiados nas memórias e na história que compartilham sobre o passado, fazem à (re)leitura de acontecimentos escolhidos como importantes, para afirmarem direitos, mesmo em meio às tantas adversidades, perseguições e violências, enquanto um povo indígena.
\end{abstract}

Palavras-chave: Xukuru do Ororubá; Pesquisas; História.

\section{INDIANS CHALLENGES RESEARCH AND HISTORICAL REFLECTIONS}

\begin{abstract}
Several studies have been conducted over the last twenty years on the so-called "mixed Indians" in the Northeast. Groups mobilized since the early decades of the twentieth century for rights claims calling into question beliefs and claims about indigenous disappearance in the Region, and which have gained considerable sociopolitical visibility in recent years. Therefore, constituting a theme to be discussed in the area of History, despite prejudices and the almost unknown, expressed by the still little research on the subject in this area of study. From a research carried out on the Xukuru Ororubá, in habitants of Pesqueira and Poção / PE, we seek to highlight how the indigenous people, based on their memories and history, share the past (re) reading of events chosen as important to affirm rights, even in the midst of so much adversity, persecution and violence, as an indigenous people.
\end{abstract}

Keywords: Xukuru do Ororubá; Researches; Story.

\section{LOS INDIOS DESAFÍAN LA INVESTIGACIÓN Y LAS REFLEXIONES HISTÓRICAS}

Resumen: Se han realizado varios estudios en los últimos veinte años sobre los llamados "indios mixtos" en el noreste. Los grupos se movilizaron desde las primeras décadas del siglo XX para reclamar derechos, cuestionando creencias y reclamos sobre la desaparición indígena en la Región, y que han ganado considerable visibilidad sociopolítica en los últimos años. Por lo tanto, constituye un tema para ser discutido en el área de la Historia, a pesar de los prejuicios y lo casi desconocido, expresado por la poca investigación sobre el tema en esta área de estudio. A partir de una investigación realizada en el Ororubá Xukuru, habitantes de Pesqueira y Poção / PE, buscamos resaltar cómo los pueblos indígenas, en base a sus recuerdos e historia, comparten la (re) lectura 
pasada de eventos elegidos como importantes para afirmar los derechos, incluso en medio de tanta adversidad, persecución y violencia como pueblo indígena.

Palabras clave: Xukuru do Ororubá; Investigaciones; Historia.

\section{INTRODUÇÃO}

A partir da segunda metade do século XIX intensificou-se as afirmações oficiais sobre o desaparecimento dos índios no Nordeste e em Pernambuco e a extinção dos aldeamentos. Eram discursos que justificavam a medição, demarcação e loteamento das terras indígenas, como forma de solucionar conflitos entre os índios e os invasores, legitimou arrendatários tradicionais que paulatinamente tinham se apossado das terras dos aldeamentos. Encontramos sistematicamente, nas falas das autoridades que os índios estavam "confundidos com a massa da população". Somava-se à negação da identidade dos índios, muitos pedidos de invasores dos territórios indígenas e autoridades, para declaração legal da extinção dos aldeamentos, em razão do suposto desaparecimento dos grupos indígenas (Porto Alegre, 1992/1993; Silva, 1995; 1996).

A extinção dos aldeamentos estava baseada na ideia de assimilação dos índios, como enfatizava uma autoridade: "Hoje talvez fosse mais conveniente confundir esse resto de índios com a massa da população; e o governo dispor de suas terras como melhor lhe parecesse; porque isto de Aldêas é uma chimera"1 (grifamos). Com essa ideia que as aldeias eram fantasias, e por essa razão não havia o porquê de existirem, posseiros, senhores de engenho e latifundiários, sobretudo após a Lei de Terras de 1850, como se constata na documentação pesquisada, ampliaram suas invasões nas terras dos antigos aldeamentos em Pernambuco. Os habitantes dos lugares onde existiram antigos aldeamentos passaram a ser chamados de caboclos, condição que muitas vezes assumiram para esconder a identidade indígena diante das inúmeras perseguições.

A essas populações foram dedicados estudos sobre seus hábitos e costumes, considerados exóticos, suas danças e manifestações folclóricas, consideradas em vias de extinção, como também aparecerem nas publicações de escritores regionais, cronistas e memorialistas municipais que exaltam de forma idílica "a contribuição indígena" nas origens e formação social de cidades no interior do Nordeste. Essas ideias foram e continuam sendo reproduzidas em escritos literários e estudos acadêmicos posteriores.

A imagem do caboclo aparece em obras literárias sobre fatos pitorescos, recordações, "estórias" das regiões Agreste e Sertão pernambucano. Como personagens típicos e curiosos que buscavam se adaptar às novas situações de sem-terras, vagando em busca de trabalho para sobrevivência. Escritores e vários estudiosos, como Gilberto Freyre, Estevão Pinto, Câmara Cascudo, dentre outros, reafirmaram o desaparecimento dos indígenas no processo de

${ }^{1}$ Ofício de Francisco Caboim (Barão de Buíque), Diretor Geral dos Índios da Província de Pernambuco, em 15/11/1870, ao Presidente da Província. Arquivo Público Estadual/APE, Códice DII-19, folha 175. 
miscigenação racial, integração cultural e dispersão no conjunto da população regional (Silva, 2017).

As reflexões, sobra a pesquisa realizada apresentada a seguir, inserem-se dentre aqueles estudos que vêm sendo elaborados nos últimos vinte anos sobre os chamados "índios misturados" no Nordeste (Oliveira, 2004). Esses grupos, que se mobilizam desde as primeiras décadas do século XX, colocando em questão crenças e afirmações sobre o desaparecimento indígena na Região, conquistaram considerável visibilidade sociopolítica em anos recentes. Constituindo-se, portanto, em um tema a ser discutido na área de História, malgrado ainda preconceitos e o quase desconhecimento, expresso pelas escassas pesquisas sobre o assunto, nessa área de estudo.

Com base em uma pesquisa documental e principalmente em relatos das memórias orais de índios Xukuru do Ororubá, buscamos compreender como esse povo, a partir das experiências vivenciadas, estabeleceu relações com a história e expressando às interpretações que fazem do passado (Monteiro, 1999) em razão das situações no presente diante dos conflitos nas disputas pelas terras que reivindicavam e na afirmação identitária indígena.

\section{METODOLOGIA}

\section{Estradas, caminhos e veredas na Serra do Ororubá: as trilhas de uma pesquisa}

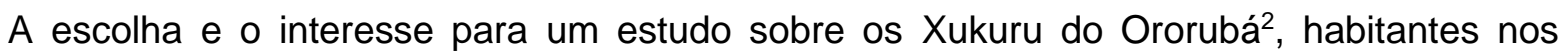
municípios de Pesqueira e Poção/PE, ocorreu entre os povos indígenas que vivenciaram a chamada "emergência étnica", esse povo ocupou e ocupa um lugar de destaque em meio às disputas, articulações políticas e mobilizações por direitos afirmados. Seja nos embates contra os fazendeiros invasores do território reivindicado por esses indígenas, seja junto aos órgãos públicos, na busca pelo reconhecimento e garantia de seus direitos, ou ainda nas articulações com a chamada sociedade civil.

Em meados dos anos 1980 os Xukuru do Ororubá participaram ativamente nos debates em torno da Assembleia Nacional Constituinte e para elaboração da nova Constituição aprovada em 1988. Apoiados pelo Conselho Indigenista Missionário-Regional Nordeste (Cimi-NE), grupos de Xukuru do Ororubá, juntamente com os de outros povos indígenas no Nordeste, viajaram por diversas vezes a Brasília/DF, onde participaram de encontros de estudos, seminários, etc., e para fazer pressões sobre os deputados que discutiam a elaboração da nova Constituição.

A presença dos Xukuru na Capital Federal, em conjunto com índios vindos das demais regiões do Brasil, num momento político tão significativo, em muito impulsionou a organização e

\footnotetext{
${ }^{2}$ Os Xukuru afirmam ter escolhido a autodenominação Xukuru do Ororubá, para não serem confundidos pelos não-índios (leia-se a imprensa e a sociedade em geral) e com um outro povo indígena, os Xukuru-Kariri em sua a maioria habitando no Município de Palmeira dos Índios/AL. Em 2003 após conflitos internos provocado incialmente por um grupo dissidente resultou em violências e assassinatos na Aldeia Vila de Cimbres. Famílias indígenas expulsas do território Xukuru do Ororubá, se autoproclamaram "Xukuru de Cimbres" e atualmente são reconhecidas como um povo indígena habitando na área urbana de Pesqueira e em um território que compreende parte dos municípios vizinhos de Alagoinha, Venturosa e Pedra.
} 
mobilização Xukuru nas reivindicações pelas terras. Após retornarem da Capital Federal, assessorados pelos missionários do Cimi-NE os Xukuru promoveram reuniões em várias localidades na Serra do Ororubá, para relatar os acontecimentos vivenciados em Brasília, bem como tratar sobre os direitos indígenas garantidos na nova Constituição. Nesse processo, destacouse a liderança de Francisco de Assis Araújo, o "Xicão", que, mais tarde, seria escolhido Cacique do povo Xukuru do Ororubá.

No final dos anos 1980 a afirmação dos indígenas pelo direito às terras reivindicadas, acirrou os conflitos entre os índios e os fazendeiros na Serra do Ororubá. E nesse período os indígenas repetidamente se reportaram aos acontecimentos do passado, para legitimar os direitos sobre 0 território reivindicado. Essas memórias remetem ao século XIX quando da participação dos índios, como voluntários da pátria, na Guerra do Paraguai, e o processo de extinção do Aldeamento de Cimbres, na Serra do Ororubá, em 1879. Ao afirmarem os direitos sobre as terras onde habitam, em constantes conflitos com os fazendeiros invasores, os Xukuru declaram que esses direitos Ihes foram garantidos pelo Governo Imperial, como recompensa pela participação dos seus antepassados na Guerra do Paraguai.

\section{As memórias como fontes para a pesquisa histórica}

Os conflitos entre os Xukuru e os fazendeiros tornaram-se mais latentes após a extinção do Aldeamento de Cimbres, em fins do século XIX. Nos anos seguintes os Xukuru tiveram a identidade indígena sistematicamente negada, sendo considerados e chamados de caboclos. Oficialmente não tinham o mínimo dos direitos reconhecidos, como as pensões previstas em lei para os descendentes dos ex-combatentes naquela Guerra. Essa situação e as condições em que viviam, com suas terras espoliadas, motivaram a articulação de apoio para uma mobilização Xukuru, em meados dos anos 1950, em busca da assistência do Serviço de Proteção aos Índios (SPI) que atuava no Nordeste desde as primeiras décadas do Século XX, junto aos Fulni-ô um povo indígena vizinho habitando em Águas Belas/PE (Silva, 2005).

A conquista do reconhecimento pelo SPI, porém, não pôs fim aos conflitos por terras, uma vez que o órgão governamental não tinha uma política fundiária para os índios no Nordeste, permanecendo as disputas nos anos seguintes. O estudo, portanto, procurou a partir das memórias orais Xukuru do Ororubá e registros escritos, compreender as conexões temporais entre as mobilizações indígenas pelas terras, nos anos 1980, e as ocorridas na década de 1950, quando os índios conquistaram o reconhecimento oficial, com a implantação de um Posto do SPI na Serra do Ororubá.

Em ambos os períodos, os Xukuru afirmaram seus direitos baseados nas memórias que seus antepassados receberam as terras como recompensa pela participação na Guerra do Paraguai, em um contexto de disputas pelas terras do oficialmente extinto Aldeamento de Cimbres/Ororubá, em fins do século XIX. Procuramos então evidenciar os nexos estabelecidos 
pelos índios, por meio de suas memórias orais, com o século XIX e os anos 1950/1960, e ainda em fins da década de 1980, quando ocorreu o acirramento dos conflitos nas disputas entre índios e fazendeiros pelas terras na Serra do Ororubá, após a participação dos índios nas discussões para a elaboração e aprovação da Constituição em 1988, que garantiu os direitos indígenas.

A partir da pesquisa das memórias em fontes escritas, buscamos evidenciar como os Xukuru do Ororubá vivenciaram diferentes situações e elaboraram estratégias para afirmação da identidade e reivindicação dos direitos sobre as terras. Para a elaboração do estudo foram realizadas diversas entrevistas e registrados relatos orais das memórias indígenas. Utilizamos também, em alguns momentos, além de uma coletânea de entrevistas publicadas, as informações coletadas por outros estudiosos que pesquisaram aquele povo com diferentes abordagens e em diferentes áreas de estudos.

Realizamos uma pesquisa documental em diferentes fontes manuscritas e impressas dos séculos XIX e XX, somando-se a consulta em jornais publicados em Pesqueira e no Recife, entre os anos 1940-1980, disponíveis no Arquivo Público de Pernambuco e microfilmados na Fundação Joaquim Nabuco, no Recife. Além disso, buscamos fontes em outros arquivos, como os documentos produzidos por Curt Nimuendajú disponíveis no Museu do Estado de Pernambuco (MEPE) e no Museu Nacional/RJ, com informações sobre os Xukuru em correspondências pessoais, fotografias e relatórios elaborados pelo alemão, que esteve na Serra do Ororubá no início dos anos 1930 (Silva, 2017).

Como também consultamos, no acervo do Museu do Índio/RJ, a documentação do SPI sobre o Posto Indígena Xucuru e os registros da Inspetoria 4a Regional do SPI, relacionados àquele povo. Acrescentamos ainda ao texto ao estudo realizado na época algumas imagens das fontes pesquisadas, no sentido de contribuir para uma maior compreensão do assunto estudado. A pesquisa em documentos históricos procurou situar os acontecimentos a que remetem as memórias indígenas, todavia tendo presente os interesses na produção desses documentos, em sua maioria nem sempre favorável aos indígenas. Nesse sentido, evidenciamos a importância dos relatos das memórias orais, isso porque,

(...) o uso das fontes orais permite não apenas incorporar indivíduos ou coletividades até agora marginalizados ou pouco representados nos documentos arquivísticos, mas também facilita o estudo de atos e situações que a racionalidade de um momento histórico concreto impede que apareçam nos documentos escritos. Assim, portanto, as fontes orais possibilitam incorporar não apenas indivíduos à construção do discurso do historiador, mas nos permite conhecer e compreender situações insuficientemente estudadas até agora (Garrido, 1992/1993, p. 36).

As entrevistas foram realizadas a partir de questões abertas, para favorecer ao/à entrevistado/a um relato mais livre e amplo, interrompidos algumas vezes quando necessário um melhor esclarecimento sobre a narrativa. Privilegiamos entrevistar índios/as mais idosos/as, 
pessoas com idades entre 50 e até mais de 80 anos, que em seus relatos rememoram lembranças de vivências da infância e juventude. Objetivando informações sobre a questão da terra, os conflitos com os fazendeiros, as disputas internas, as relações de trabalho, o cotidiano, as formas de lazer, as cerimônias e os ritos religiosos, as memórias sobre a Guerra do Paraguai, as mobilizações para a instalação e as relações com o Posto do SPI, e também quais os indícios que aparecem sobre essas situações na documentação pesquisada.

Em um primeiro momento foi discutido como, desde os fins do século XIX, após a extinção dos aldeamentos e até os anos 1960, as autoridades oficiais e diferentes pesquisadores em artigos e livros publicados sistematicamente questionaram ou negaram a existência de uma população indígena na Serra do Ororubá, onde atualmente habitam os Xukuru do Ororubá. Confrontamos esses discursos que negavam os indígenas, com as reflexões do antropólogo João Pacheco de Oliveira sobre os índios e os processos de territorialização no Nordeste contemporâneo.

Procuramos evidenciar como os Xukuru do Ororubá recorrem às memórias sobre a Guerra do Paraguai, para afirmar a legitimidade de suas reivindicações do território disputado com os fazendeiros. A partir de uma discussão fundamentada nas narrativas dos entrevistados e na pesquisa documental, situamos o quadro histórico ao qual se remetiam as narrativas das memórias indígenas. A descrição da Serra do Ororubá enquanto espaço de disputas entre índios pequenos agricultores e fazendeiros, foi realizada a partir de relatos orais que os indígenas ouviram de seus antepassados sobre a posse e o uso da terra. E de uma bibliografia onde foram citados relatos e esboçadas imagens do final do século XIX e início do século XX, sobre as condições ambientais na Serra, invadida pelos grandes criadores de gado, e nas áreas úmidas por engenhos de cana produtores de rapadura, com o trabalho da mão-de-obra indígena.

Foram evidenciados ainda os sítios enquanto espaços de sociabilidades por meio das festas, novenas, o trabalho em mutirão e as relações do cotidiano. E a Vila de Cimbres pensada como espaço de identidade e de memórias, expressas nas festas religiosas e rituais anuais e, principalmente, na dança do Toré. Baseando-se nas memórias orais indígenas, foram apresentados e discutidos os deslocamentos de indígenas que, em virtude das terras para plantar e viver estarem invadidas pelos criadores de gado, ou pelos plantios destinados à fábrica Peixe, fundada pela família Brito, em 1902 (Sette, 1956), ou ainda por causa das secas que periodicamente atingiram a Serra do Ororubá, foram trabalhar como operários nas indústrias urbanas em Pesqueira. Ou migraram para trabalhar na lavoura canavieira na Zona da Mata Sul pernambucana e Norte de Alagoas ou nas plantações de algodão no Sertão da Paraíba.

Foi analisado, ainda, o período das relações dos índios com o SPI. Com base em registros oficiais e em memórias indígenas dos primeiros contatos dos índios com o órgão indigenista oficial, abordamos a viagem a pé realizada por três xukurus ao Rio de Janeiro, onde foram falar com Rondon, conseguindo a instalação de um Posto do órgão indigenista na Serra. Discutimos ainda, a partir da documentação do órgão indigenista e relatos indígenas, as relações com o Posto Xucuru 
e os conflitos resultantes da instalação do Posto no Sítio São José e não em Brejinho, de onde partiram os índios que foram ao Rio de Janeiro.

A mobilização e participação dos Xukuru nas Ligas Camponesas em Pesqueira, na ocupação da área da Pedra d'Água, foi outro momento da história dos indígenas analisado a partir de registros das memórias orais, jornais, da documentação do Dops e relatórios oficiais do período. Foram evidenciadas as memórias indígenas sobre a participação em uma polícia indígena, na organização camponesa e na ocupação da citada área, em um quadro social de exploração, conflitos, violências e expulsões dos antigos moradores indígenas com o avanço agroindustrial na Serra do Ororubá.

Liderados pelo Cacique "Xicão" posteriormente os Xukuru do Ororubá iniciaram as retomadas das terras sob o domínio dos fazendeiros, justificando seus direitos baseados nas memórias, afirmando que as terras foram recebidas recompensas pela participação de seus antepassados como voluntários na Guerra do Paraguai. As memórias indígenas situam-se na dinâmica das experiências históricas, a partir do vivido, o concebido e o expressado. As análises em nossa pesquisa foram alicerçadas pelas reflexões de estudos sobre as memórias e as suas relações com a História, em autores clássicos como Maurice Halbwachs, como também nas ideias mais recentes de Michael Pollak e Verena Alberti, sobre o assunto.

Permeando a abordagem ainda uma visão em abertura para os diálogos multidisciplinares com as recentes discussões antropológicas sobre os índios no Nordeste, que favoreceram o estudo realizado. A bibliografia utilizada em razão da documentação primária e das obras datadas analisadas, bem como as abordagens que adotamos, foram baseadas na produção mais recente a respeito dos temas presentes no estudo e sobre os povos indígenas. Nesse sentido, além das produções atuais e os vários artigos publicados em periódicos que de alguma forma trataram de temas relacionados à nossa pesquisa, recorremos também a dissertações e teses acadêmicas.

\section{RESULTADOS E DISCUSSÕES}

\section{Índios na Serra do Ororubá: uma história de experiências}

A participação nos eventos em torno da Constituinte em muito impulsionou a organização e mobilizações Xukuru do Ororubá. Durante as várias estadas em Brasília, o Toré foi dançado em diversas vezes assumindo, além de um significado político, um marco da identidade e mobilização dos indígenas. Promulgada a Constituição e retornando da Capital Federal, assessorados pelos missionários do Cimi-NE os Xukuru do Ororubá promoveram em Cana Brava uma reunião acompanhada de muito Toré, com índios das diversas aldeias na Serra do Ororubá, para relatar os acontecimentos vivenciados em Brasília, bem como tratar dos direitos indígenas garantidos na nova Constituição (Silva, 2017).

Portanto, as memórias Xukuru foram retomadas pelos indígenas no início dos anos 1950, quando buscaram os benefícios da lei para familiares de ex-combatentes na Guerra do Paraguai e 
o reconhecimento oficial para a instalação de um Posto do SPI na Serra do Ororubá. Como também em fins dos anos 1980, quando, após participarem nas discussões e mobilizações para a elaboração da nova Constituição Federal que garantiu os direitos indígenas, passaram a reivindicar as suas terras invadidas por fazendeiros. Naquela década quando os conflitos por terras e os direitos indígenas em Pesqueira ocuparam o espaço público de debates por meio da imprensa, os Xukuru do Ororubá recorreram as suas memórias para contrapor as afirmações contrárias à existência indígena por parte dos fazendeiros.

Por meio da pesquisa das memórias, percebemos elos de uma história coletiva, de um pertencimento, em um conjunto de situações e experiências históricas que conferem uma identidade, baseada em um espaço ancestral comum, a Serra do Ororubá. Sendo possível afirmar a existência de uma memória coletiva: "A memória coletiva aparece como um discurso da alteridade, no qual a posse de uma história que não se divide, dá ao grupo sua identidade" (Godoi, 1999).

Uma memória compondo um patrimônio dinâmico e, a exemplo do ocorrido em outros lugares e situações, "Verifica-se que ela é ativada num contexto de pressão sobre o território do grupo, atuando como criadora de solidariedades, produtora de imaginário, erigindo regras de pertencimento e exclusão, delimitando as fronteiras sociais do grupo" (Godoi, 1999). As memórias orais dos Xukuru do Ororubá sobre a Guerra do Paraguai ocupam um lugar central nas leituras que fazem da História para afirmarem o direito às terras. Conquistadas como recompensa pela participação de seus antepassados naquela Guerra.

Nas entrevistas foi lembrado sobre o famoso batalhão "30 do Ororubá", relatando como índios Xukuru voluntários da Pátria, após lutarem e vencerem a Guerra do Paraguai foram recebidos pessoalmente, no Rio de Janeiro, pelo casal imperial que teriam retribuído a participação dos indígenas na Guerra em defesa do Brasil com as terras reivindicadas pelos indígenas. A história contada pelos Xukuru do Ororubá é pontuada por acontecimentos, momentos e marcos que consideram fundamentais tais como: a participação na Guerra do Paraguai, a época da busca pelo reconhecimento do SPI nos anos 1950, e o período da mobilização para as retomadas das terras nos anos 1980, sob a liderança do Cacique Xicão. As memórias sobre a participação dos Xukuru na Guerra do Paraguai, portanto, são relidas em diferentes contextos.

\section{CONSIDERAÇÕES FINAIS}

Nos relatos das memórias orais dos Xukuru do Ororubá, percebemos outros momentos que expressaram o cotidiano, os espaços de sociabilidades criados na Serra do Ororubá, os significados de Cimbres como um espaço de referências das memórias mítico-religiosa para a afirmação da identidade dos indígenas, as relações de trabalho com os fazendeiros ou como operários nas agroindústrias em Pesqueira. E ainda nas atividades exercidas para sobrevivência, por falta de terras e em razão da seca, na lavoura canavieira na Zona da Mata Sul pernambucana e Norte alagoana, ou nas plantações de algodão no Sertão paraibano. São fragmentos de relatos 
individuais, de memórias autobiográficas, mas que fazem parte de uma história coletiva, na medida em que toda memória individual se apoia na memória grupal, pois toda história de vida faz parte da história em geral (Halbwachs, 2004).

Analisando os relatos dos Xukuru do Ororubá, foi possível concluir, como afirmou Michael Pollak, quando discutiu sobre memória e identidade social, que, entre os Xukuru do Ororubá é "perfeitamente possível que por meio da socialização política, ou da socialização histórica, ocorra um fenômeno de projeção ou de identificação com determinado passado, tão forte que podemos falar numa memória quase herdada". (Pollak, 1992). Compreender o significado das memórias orais Xukuru do Ororubá é compreender a "história de experiências" (Pollak, 1989).

Um debruçar sobre essas narrativas possibilita entender como "pessoas ou grupos efetuaram e elaboraram experiências" (Alberti, 2004). Essas experiências foram e são marcantes, porque intensamente vividas. As narrativas das memórias orais do povo Xukuru do Ororubá ajudam ainda a "entender como pessoas e grupos experimentaram o passado e torna possível questionar interpretações generalizantes de determinados acontecimentos e conjunturas" (Alberti, 2004).

Procuraram apresentar os caminhos metodológicos da pesquisa realizada, onde buscamos evidenciar como os Xukuru do Ororubá, apoiados nas memórias e na história que compartilham sobre o passado, fazem à (re)leitura de acontecimentos escolhidos como importantes, para afirmarem seus direitos, mesmo em meio às tantas adversidades, perseguições e violências, enquanto um povo indígena, a partir do vivido, do concebido e do expressado.

\section{REFERÊNCIAS}

Alberti, V. Ouvir contar: textos em História Oral. Rio de Janeiro, FGV, 2004.

Garrido, J. D. A. As fontes orais na pesquisa histórica: uma contribuição ao debate. Revista Brasileira de História, 13(25/26), 33-54, 1992/1993.

Godoi, E. P. O trabalho da memória: cotidiano e história no Sertão do Piauí. Campinas, Editora da UNICAMP, 1999.

Halbwachs, M. A memória coletiva. São Paulo, Centauro, 2004.

Monteiro, J. M. Armas e armadilhas. In: NOVAES, Adauto. (Org.). A outra margem do Ocidente. São Paulo, Cia. das Letras, 1999, p.237-249.

Oliveira, J. P. (Org.). A viagem de volta: etnicidade, política e reelaboração cultural no Nordeste indígena. $2^{a}$ ed. Rio de Janeiro, Contra Capa Livraria, 2004.

Pollak, M. Memória e identidade social. In: Estudos Históricos. Rio de Janeiro, 1992, 5(10), p. $200-$ 212.

Pollak, M. Memória, esquecimento, silêncio. Estudos Históricos, 2(3), 3-15, 1989.

Porto Alegre, M. S. Cultura e História, sobre o desaparecimento dos povos indígenas. Revista de Ciências Sociais, 23/24(1/2), 213-225, 1992/1993. 
Sette, H. Pesqueira: aspectos de sua Geografia Urbana e de suas inter-relações regionais. Tese de concurso para provimento efetivo da cadeira de Geografia do Brasil do Colégio Estadual de Pernambuco. Recife, 1956.

Silva, E. "Confundidos com a massa da população": o esbulho das terras indígenas no Nordeste do século XIX. Revista do Arquivo Público Estadual de Pernambuco, 46(42), 17-29, 1996.

Silva, E. Memórias Xukuru e Fulni-ô da Guerra do Paraguai. Ciência em Revista. 3(2), 51-58, 2005.

Silva, E. O lugar do índio. Conflitos, esbulhos de terras e resistência indígena no século XIX: o caso de Escada - PE (1860-1880). Dissertação (Mestrado em História) - Universidade Federal de Pernambuco, Recife. 1995.

Silva, E. Xukuru: memórias e história dos índios da Serra do Ororubá (Pesqueira/PE), 1959-1988. 2a ed. Recife, EDUFPE, 2017. 